\title{
Rare single nucleotide variants in COL5A1 promoter do not play a major role in keratoconus susceptibility associated with rs1536482
}

\author{
Liubov O. Skorodumova ${ }^{1 *}$, Alexandra V. Belodedova ${ }^{1,2}$, Elena I. Sharova ${ }^{1}$, Elena S. Zakharova ${ }^{1}$, \\ Liliia N. Iulmetova', Mukharram M. Bikbov³, Emin L. Usubov³, Olga P. Antonova², Oksana V. Selezneva ${ }^{4}$, \\ Anastasia Levchenko5, Olga Yu Fedorenko $0^{6,7}$, Svetlana A. Ivanova ${ }^{6,7,8}$, Raul R. Gainetdinov ${ }^{9}$ and \\ Boris E. Malyugin²
}

\begin{abstract}
Background: Keratoconus is a chronic degenerative disorder of the cornea characterized by thinning and coneshaped protrusions. Although genetic factors play a key role in keratoconus development, the etiology is still under investigation. The occurrence of single-nucleotide polymorphisms (SNPs) associated with keratoconus in Russian patients is poorly studied. The purpose of this study was to validate whether three reported keratoconus-associated SNPs (rs1536482 near the COL5A1 gene, rs2721051 near the FOXO1 gene, rs1324183 near the MPDZ gene) are also actual for a Russian cohort of patients. Additionally, we investigated the COL5A1 promoter sequence for single-nucleotide variants (SNVs) in a subgroup of keratoconus patients with at least one rs1536482 minor allele (rs1536482+) to assess the role of these SNVs in keratoconus susceptibility associated with rs 1536482.
\end{abstract}

Methods: This case-control study included 150 keratoconus patients and two control groups (main and additional, 205 and 474 participants, respectively). We performed PCR targeting regions flanking SNVs and the COL5A1 promoter, followed by Sanger sequencing of amplicons. The additional control group was genotyped using an SNP array.

Results: The minor allele frequency was significantly different between the keratoconus and control cohorts (main and combined) for rs1536482, rs2721051, and rs 1324183 ( $p$-value <0.05). The rare variants rs 1043208782 and rs569248712 were found in the COL5A1 promoter in two out of 94 rs1536482+ keratoconus patients.

Conclusion: rs1536482, rs2721051, and rs1324183 were associated with keratoconus in a Russian cohort. SNVs in the COL5A1 promoter do not play a major role in keratoconus susceptibility associated with rs 1536482.

Keywords: Keratoconus, Cornea, SNP, GWAS, Genotyping, Promoter, COL5A1, MPDZ, FOXO1

*Correspondence: lo.skorodumova@gmail.com

${ }^{1}$ Laboratory of Human Molecular Genetics, Federal Research and Clinical Center of Physical-Chemical Medicine of Federal Medical Biological Agency, 1a Malaya Pirogovskaya UI, Moscow, Russian Federation 119435

Full list of author information is available at the end of the article

\section{Background}

Keratoconus is the most common primary ectatic disorder associated with thinning, stretching, and conical protrusion of the central part of the cornea. The progression of this disease can lead to severe visual impairment due to corneal irregularities and scarring. The disease most often manifests in adolescence and progresses within original author(s) and the source, provide a link to the Creative Commons licence, and indicate if changes were made. The images or other third party material in this article are included in the article's Creative Commons licence, unless indicated otherwise in a credit line to the material. If material is not included in the article's Creative Commons licence and your intended use is not permitted by statutory regulation or exceeds the permitted use, you will need to obtain permission directly from the copyright holder. To view a copy of this licence, visit http://creativecommons.org/licenses/by/4.0/. The Creative Commons Public Domain Dedication waiver (http://creativeco mmons.org/publicdomain/zero/1.0/) applies to the data made available in this article, unless otherwise stated in a credit line to the data. 
10-15 years [1]. Keratotopography- and optical coherence tomography-based approaches have improved the diagnosis of early-stage keratoconus. However, the diagnosis of subclinical keratoconus remains a challenge [2]. The presence of undiagnosed disease in a patient can lead to severe complications after laser refractive interventions, such as the manifestation of reactive keratoconus and its atypical progression $[3,4]$. Thus, the development of approaches for the early diagnosis of keratoconus is highly clinically relevant.

Understanding the genetic basis of keratoconus can facilitate its early diagnosis [5]. The genetic nature of keratoconus has been revealed, and many studies have been conducted to search for loci associated with this disease [5-14]. Recently, it was found that several loci are repeatedly associated with keratoconus in large European ancestry cohorts. Among them are loci near the COL5A1 gene, near the FOXO1 gene, and near the MPDZ gene. Initially, all three loci were discovered to be associated with central corneal thickness in GWASs [15-17]. Then, this association extended to keratoconus cohorts: the association was replicated in candidate gene studies and GWASs $[8,10,11,13,14]$. Loci near FOXO1 and MPDZ were also associated with corneal hysteresis and corneal resistance factors $[18,19]$.

Keratoconus susceptibility loci, even those reported previously, are poorly studied in Russian patients with keratoconus. Patients with keratoconus from Russia were previously genotyped for rs1536482 and rs7044529 in our pilot study on a small sample [20].

This study aimed to investigate the replication of three SNPs (rs1536482 near the COL5A1 gene, rs2721051 near the FOXO1 gene, rs1324183 near the MPDZ gene) with keratoconus in the largest sample of patients from Russia. Additionally, we investigated rare variants in the COL5A1 promoter of keratoconus patients with at least one rs1536482 minor allele.

\section{Methods}

\section{Ethical statements}

The Institutional Review Boards of the S. Fyodorov Eye Microsurgery Complex Federal State Institution, the Federal Research and Clinical Center of Physical-Chemical Medicine, and the Ufa Eye Research Institute approved this study. It was conducted in compliance with the tenets of the Declaration of Helsinki. All subjects signed written informed consent forms.

\section{Keratoconus patients}

Clinically affected patients with keratoconus were recruited at the S. Fyodorov Eye Microsurgery Complex Federal State Institution and the Ufa Eye Research Institute. All patients underwent clinical and functional examination, visual acuity testing, refractometry, ophthalmometry, biomicroscopy, and ophthalmoscopy. During slit-lamp examination, surface asphericity and the presence of thinning, Vogt's striae, Fleischer's rings, Descemet's membrane folds, and stromal scarring were evaluated. Keratoconus patient corneas were also assessed using optical coherence tomography Visante OCT (Carl Zeiss; Oberkochen, Germany) and corneal topography TMS-4 (Tomey; Nagoya, Japan). Characteristic keratoconus patterns of corneal topography images (asymmetry, scatter of axes, a difference in keratometry along one axis (irregular astigmatism)), increased surface asymmetry index and surface regularity index values (>1) along with a central thickness of less than $480 \mathrm{~nm}$, and an inability to correct visual acuity to $1.0(20 / 20)$ were critical for the differential diagnosis of early disease. The keratoconus stage was determined according to the Amsler-Krumeich classification [21]. Patients with at least stage 1 keratoconus were included; patients with subclinical keratoconus were not included in this study. The patients were graded as follows: stage $1, n=9$; stage $2, n=39$; stage $3, n=85$; and stage $4-n=17$. Patients with syndromic keratoconus, in whom keratoconus was only one of the symptoms of a multisystem disease (for example, Down's syndrome), were excluded. The patients were all of the European descent.

Patients diagnosed with keratoconus were also asked if they would agree to invite first-degree relatives. If they agreed, then their relatives were invited and consulted about participation in the study. After obtaining written informed consent, the relatives were examined in the same way as the keratoconus patients. Participation also meant that blood collection was allowed. For 50 of the patients with keratoconus, the material was also obtained from relatives. The relatives' DNA was used only for the cosegregation analysis of variants found in the COLSA1 promoter.

\section{Main control group}

Participants in the main control group $(n=205)$ were evaluated at the S. Fyodorov Eye Microsurgery Complex Federal State Institution and the Ufa Eye Research Institute. Medical history collection and a thorough ophthalmic examination were carried out for all potential participants. Patients with keratoconus, glaucoma, medium- to high-degree myopia, or retinal or corneal dystrophy were not included. Acceptable ocular diseases included mild myopia, pseudoexfoliation syndrome, and senile (age-related) cataracts. No subjects with a medical history of early-onset cataracts were included, as earlyonset anterior polar cataracts are associated with keratoconus [22]. Participants from the control group were of European descent. 


\section{Additional control group}

A control group of 503 participants, described by Levchenko A. et al., was included as an additional control group [23]. Briefly, control participants were recruited as volunteers from university teaching personnel and students, employees of local medical and emergency service institutions, and at-large community members in Tomsk, Kemerovo, and Novosibirsk (245 (48.71\%) males, mean age 31.2 (SD 9.8); 258 (51.29\%) females, mean age 34.0 (SD 15.4); total mean age 32.6 (SD 13.0)). The participants did not undergo an ophthalmologic examination, but since the prevalence of keratoconus in the general population is low, this is unlikely to have an effect on the results.

\section{Blood collection and DNA extraction}

Venous blood (4-6 mL) was collected from each participant in Vacutainer tubes with EDTA (Becton, Dickinson and Company; New Jersey, USA). The samples were stored at $-20^{\circ} \mathrm{C}$ until genetic study. DNA was isolated from blood samples with the Gentra Puregene Blood Kit (Qiagen; Hilden, Germany) according to the manufacturer's protocol. DNA was resuspended in low-TE buffer at a final concentration of $10 \mathrm{ng} / \mu \mathrm{l}$.

\section{Genotyping of candidate SNVs}

SNV genotyping was carried out by Sanger sequencing. The primer sequences for rs1324183 and rs2721051 were obtained from an article by Liskova P. et al. (Table 1) [11]. Other primers were designed with Primer-BLAST (provided in the public domain by the National Center for Biotechnology Information, Bethesda, MD, USA;
Table 1). The applied PCR conditions are described below. ABI sequencing files were analyzed in UniPro UGENE (v37.0) [24].

\section{COL5A1 gene promoter sequencing}

To evaluate COL5A1 promoter variants, we sequenced the NC_000009.12:134,641,188-134,642,551 region (between 1000 nucleotides upstream of the COL5A1 transcription start site and the $3^{\prime}$-side of the CpG island in the first exon) [25]. This region also included the promoter-like signature EH38E2735243 [26]. Primers for the promoter region were designed using Primer-BLAST (Table 2). The PCR conditions and the sequencing procedure are described below. Sanger chromatograms were processed with variant analysis software from the cloud dashboard of ThermoFisher Scientific (Waltham, Massachusetts, USA), Unipro UGENE, and Nucleotide BLAST software (provided in the public domain by the National Center for Biotechnology Information, Bethesda, MD, USA).

\section{PCR and sanger sequencing}

For the amplification of target sequences, we used the Gene Pak PCR MasterMix Core Kit (IsoGene Lab. Ltd.; Moscow, Russia) under the following conditions: reaction volume, $20 \mu \mathrm{l}$; DNA input, $50 \mathrm{ng}$; and final concentration for each primer, $0.3 \mathrm{nM}$. Sanger sequencing was carried out according to the manufacturer's protocol with the BigDye Terminator v3.1 Kit (Thermo Fisher Scientific) on an ABI Prism 3730XL Genetic Analyzer (Applied Biosystems Inc.; Waltham, Massachusetts, USA).

Table 1 Primers Used for Keratoconus-Associated SNV Genotyping

\begin{tabular}{|c|c|c|}
\hline dbSNP identification number & Forward primer sequence $5^{\prime}>3^{\prime}$ & Reverse primer sequence $5^{\prime}>3^{\prime}$ \\
\hline rs1536482 & AGGTCCCTTGAGCCCTTTTA & TCACCTGAGCCTCCTCATCG \\
\hline rs2721051 & CCAAGGTTAACCGAAGTCCA ${ }^{\mathrm{a}}$ & AAGGGAAGAGGCAAATGTGA ${ }^{a}$ \\
\hline \multirow[t]{2}{*}{ rs1324183 } & TATTGATCCACAGCCAGCAG & AAGCGCTTCTAAAAGCCAATC ${ }^{a}$ \\
\hline & ACAGCCAGCAGGAAGAGAACAT & ACAGTGACTTCCTCAGACTGGC \\
\hline
\end{tabular}

a Primers from Liskova P. et al. [11]

Table 2 Primers Used for COL5A1 Gene Promoter Sequencing

\begin{tabular}{llll}
\hline Primer pair name & Genomic coordinate GRCh38 & Forward primer sequence $\mathbf{5}^{\prime} \mathbf{>}^{\mathbf{3}}$ & Reverse primer sequence $\mathbf{5}^{\prime} \mathbf{>} \mathbf{3}^{\prime}$ \\
\hline COL5A1-F/R4 & chr9:134641407-134,641,983 & CGAAGTGATCAAACCTCGGG & GCTCGACTTTGGCCGC \\
COL5A1-F/R6 & chr9:134640893-134,641,555 & GAGAGACGCCCACCTACCAC & TTCTCTGAGAGCCGGTAGGC \\
COL5A1-F/R7 & chr9:134641693-134,642,213 & CCGGGCTCTGATTTGCTG & GCTTTCCAGCGGGTATGGA \\
COL5A1-F/R8 & chr9:134642371-134,643,040 & CTTCGCCCGCAGAACTTTC & TCATCCCAACCACTCACAGC \\
COL5A1-F/R9 & chr9:134642076-134,642,671 & CTAAAGTGGTGCGGTCCCTG & GTTCTGCTGTAGGGCTGTGA \\
\hline
\end{tabular}




\section{SNP array analysis}

An additional control group was genotyped by Levchenko A. et al. using the iScan System and the Infinium Global Screening Array-24 v1.0 BeadChip (Illumina; San Diego, California, USA) [23]. We converted the SNP array data to PLINK format to perform basic quality control steps using PLINK (v1.9 and v2.0) [27]. We established a quality filter with a threshold of $10 \%$ for the SNP missing rate. All individuals exhibiting more than $7 \%$ missingness, outlying heterozygosity, 2nd-degree or closer relationships were omitted from the calculation. A total of 474 samples and 640,014 SNPs with a $99.9 \%$ genotyping call rate passed all QC requirements and were selected for further consideration.

Genotypes were initially presented in the SNP array data for only rs1536482 and rs2721051, which could thus be directly analyzed by PLINK. The MAF and minor homozygote frequency (MHF) for rs1324183 SNV were estimated after the imputation procedure. Phasing and imputation using the 1000 Genomes Phase III reference panel were conducted with SHAPEIT (v2 (r904)) and IMPUTE2 (v2.3.2), respectively [28-30].

\section{Statistics}

We assessed the differences in allele frequencies between the control and keratoconus groups by using a two-tailed Fisher's exact test in Prism 7 (GraphPad Software Inc.; San Diego, California, USA) according to a threshold of $p<0.05$. The Hardy-Weinberg equilibrium of the genotypes in the keratoconus and control groups was tested by the chi-squared test according to a $p$-value $=0.05$. Power was calculated in G*Power software (v3.1) [31].

\section{Meta-analysis}

We included studies conducted in European-Ancestry cohorts of keratoconus patients $[6-8,10,11,14]$. Metaanalysis was conducted with the Meta package (v4.9-6) of $\mathrm{R}$ statistical software [32,33]. We used a random-effect model with the Hartung-Knapp-Sidik-Jonkman estimator for $\tau^{2}$ for effect size pooling, which is the preferred method for a small number of unequally sized studies [34]. Heterogeneity was assessed using the $I^{2}$ measure [35].

\section{Availability of data and materials}

The datasets used during the current study and $A B I$ trace files are available from the corresponding author on reasonable request.

\section{Results}

\section{Study design}

We included 150 unrelated patients with sporadic $(n=130)$ and familial keratoconus $(n=20)$. The main control group counted 205 unaffected control subjects from the European part of Russia (Table 3). The proportions of males and females in the keratoconus and main control groups did not differ significantly ( $p$-value $>0.05)$. The mean age of the subjects in the main control group was greater than that in the keratoconus group to minimize the number of participants with undiagnosed keratoconus.

Due to the lack of genome projects including large cohorts of people from Russia to strengthen the results, we included an additional control group of 474 participants genotyped using an SNP array [23]. This cohort was first used as a control population for our main control group. Then, we combined the data from the main and additional groups and recalculated the results.

\section{Genotyping of candidate SNVs}

All 150 patients with keratoconus and 205 participants from the main control group were genotyped for three SNPs: rs1536482, rs2721051, and rs1324183. Data on the occurrence of each genotype in the keratoconus and control groups are presented in Table 4. Hardy-Weinberg equilibrium was confirmed for all variants except for rs1324183 in the additional control group. We considered this deviation to be a small-sample-size effect.

\section{Minor allele frequency of candidate SNVs in the additional and Main control groups}

Two candidate SNPs, rs1536482 and rs2721051, were directly genotyped from the SNP array data for the additional control group. The IMPUTE2 info metric, which estimates the accuracy of imputation, showed a high confidence score for rs1324183. Therefore, we used the imputed rs1324183 genotypes for the additional control group in the analysis. Genotyping data are presented in

Table 3 Demographic Characteristics of the Keratoconus and Control Groups

\begin{tabular}{|c|c|c|c|c|c|}
\hline \multirow[t]{2}{*}{ Characteristic } & & \multicolumn{2}{|c|}{ Keratoconus patients $(n=150)$} & \multicolumn{2}{|c|}{ Main control group $(n=205)$} \\
\hline & & Males & Females & Males & Females \\
\hline Number (\%) & & $104(69.3 \%)$ & $46(30.7 \%)$ & $129(62.9 \%)$ & $76(37.1 \%)$ \\
\hline \multirow[t]{2}{*}{ Age } & Mean age [SD] & $31.7[9.9]$ & $33.9[11.4]$ & $59.6[10.7]$ & $67.0[10.3]$ \\
\hline & & $32.4[10.4]$ & & $62.3[11.1]$ & \\
\hline
\end{tabular}


Table 4 Genotypes of the Keratoconus and Control Groups Determined in This Study

\begin{tabular}{|c|c|c|c|c|c|c|c|}
\hline \multirow[t]{2}{*}{$\begin{array}{l}\text { dbSNP identification number } \\
\text { and related gene }\end{array}$} & \multirow[t]{2}{*}{ Genotype } & \multicolumn{3}{|c|}{$\begin{array}{l}\text { Number of subjects with the corresponding genotype, } \\
(\%)\end{array}$} & \multicolumn{3}{|c|}{ Chi-squared test $p$-value } \\
\hline & & Keratoconus group & Main control group & $\begin{array}{l}\text { Additional } \\
\text { control } \\
\text { group }\end{array}$ & $\begin{array}{l}\text { Keratoconus } \\
\text { group }\end{array}$ & $\begin{array}{l}\text { Main } \\
\text { control } \\
\text { group }\end{array}$ & $\begin{array}{l}\text { Additional } \\
\text { control } \\
\text { group }\end{array}$ \\
\hline \multirow[t]{3}{*}{ rs1536482 (near COL5A1 gene) } & A/A & $24(16.0)$ & $16(7.8)$ & $42(8.4)$ & 0.7860 & 0.9580 & 0.5653 \\
\hline & $\mathrm{G} / \mathrm{A}$ & $70(46.7)$ & $82(40.0)$ & $207(41.2)$ & & & \\
\hline & $\mathrm{G} / \mathrm{G}$ & $56(37.3)$ & $107(52.2)$ & $225(44.8)$ & & & \\
\hline \multirow[t]{3}{*}{ rs2721051 (near FOXO1 gene) } & $\mathrm{T} / \mathrm{T}$ & $2(1.3)$ & $1(0.5)$ & $4(0.8)$ & 0.8824 & 0.7061 & 0.3739 \\
\hline & $\mathrm{C} / \mathrm{T}$ & $33(22.0)$ & $22(10.7)$ & $63(12.5)$ & & & \\
\hline & $\mathrm{C} / \mathrm{C}$ & $115(76.7)$ & $182(88.8)$ & $407(80.9)$ & & & \\
\hline \multirow[t]{3}{*}{ rs1324183 (near the MPDZ gene) } & $\mathrm{A} / \mathrm{A}$ & $0(0.0)$ & $11(5.4)$ & $17(3.7)^{\mathrm{a}}$ & 0.1795 & 0.2216 & 0.0480 \\
\hline & $\mathrm{A} / \mathrm{C}$ & $23(15.3)$ & $60(29.3)$ & $111(24.0)^{\mathrm{a}}$ & & & \\
\hline & $\mathrm{C} / \mathrm{C}$ & $127(84.7)$ & $134(65.3)$ & $334(72.3)^{a}$ & & & \\
\hline
\end{tabular}

a imputed frequency

Table 4, and the MAF data are presented in Table 5. The MAFs in the main and additional control groups did not differ significantly ( $p$-value $<0.05$ for Fisher's exact test). Therefore, we merged the two control groups to increase the analysis power.

\section{Minor allele frequency assessment between the keratoconus and control groups}

The minor allele distribution was significantly different $(p$-value $<0.05)$ between the keratoconus and main control groups for all three SNPs: rs1536482 near the COL5A1 gene, rs2721051 near the FOXO1 gene, and the rs1324183 minor allele near the $M P D Z$ gene (Table 5). The MAF was also significantly different ( $\mathrm{p}$-value $<0.05$ ) between the keratoconus and combined control groups for rs1536482, rs2721051, and rs1324183 (Table 5).

The maximum post hoc power of $89.26 \%$ was achieved in the combined control group for rs1324183. rs2721051 in the combined control group showed an acceptable power of $80.04 \%$. rs 1536482 showed moderate power of $59.02 \%$ in the combined control group.
Minor allele frequencies among Russian cohort and other European-ancestry cohorts in keratoconus studies

To compare the results for our cohort with those from other reported studies on keratoconus-associated loci, we carried out a meta-analysis of rs1536482, rs2721051, and rs1324183 using the genotyping data from our keratoconus group and combined control group. The results of this analysis are provided in forest plots in Fig. 1. For rs1536482 and rs2721051, pooled effect sizes were homogeneous across studies $\left(I^{2} \leq 30 \%\right)$. For rs1324183, the $I^{2}$ value for heterogeneity was moderate $-55 \%$.

\section{SNVs in the COL5A1 promoter}

The COL5A1 promoter (NC_000009.12: 134641188$134,642,551)$ was sequenced in a subgroup of keratoconus patients with at least one rs1536482 minor allele $(n=94)$. We detected three SNVs with European population frequencies $\leq 1 \%$ according to the ALFA project: rs1043208782, rs569248712, and rs548525119 (Table 6) [36]. Cosegregation analysis was available for rs569248712 (one family) and rs548525119 (two families). Although our group was enriched with subjects

Table 5 Minor Allele Frequency in Keratoconus Patients and Control Groups

\begin{tabular}{|c|c|c|c|c|c|c|c|c|}
\hline \multirow[t]{2}{*}{$\begin{array}{l}\text { dbSNP identi- } \\
\text { fication number }\end{array}$} & \multicolumn{4}{|c|}{ Minor allele frequency } & \multicolumn{2}{|c|}{$\begin{array}{l}\text { Keratoconus vs. main } \\
\text { control group }\end{array}$} & \multicolumn{2}{|c|}{$\begin{array}{l}\text { Keratoconus vs. } \\
\text { combined control } \\
\text { group }\end{array}$} \\
\hline & $\begin{array}{l}\text { Keratoconus } \\
\text { group }\end{array}$ & $\begin{array}{l}\text { Main control } \\
\text { group }\end{array}$ & $\begin{array}{l}\text { Additional } \\
\text { control group }\end{array}$ & $\begin{array}{l}\text { Combined } \\
\text { control group }\end{array}$ & $p$-value & OR & $p$-value & OR \\
\hline rs1536482 & 0.393 & 0.278 & 0.307 & 0.298 & 0.0016 & 1.68 & 0.0016 & 1.53 \\
\hline rs2721051 & 0.147 & 0.059 & 0.075 & 0.070 & 0.0001 & 2.76 & $4.60^{-05}$ & 2.29 \\
\hline rs1324183 & 0.290 & 0.200 & $0.157^{\mathrm{a}}$ & 0.169 & 0.0058 & 1.63 & $4.00^{-06}$ & 2.01 \\
\hline
\end{tabular}

a imputed frequency 


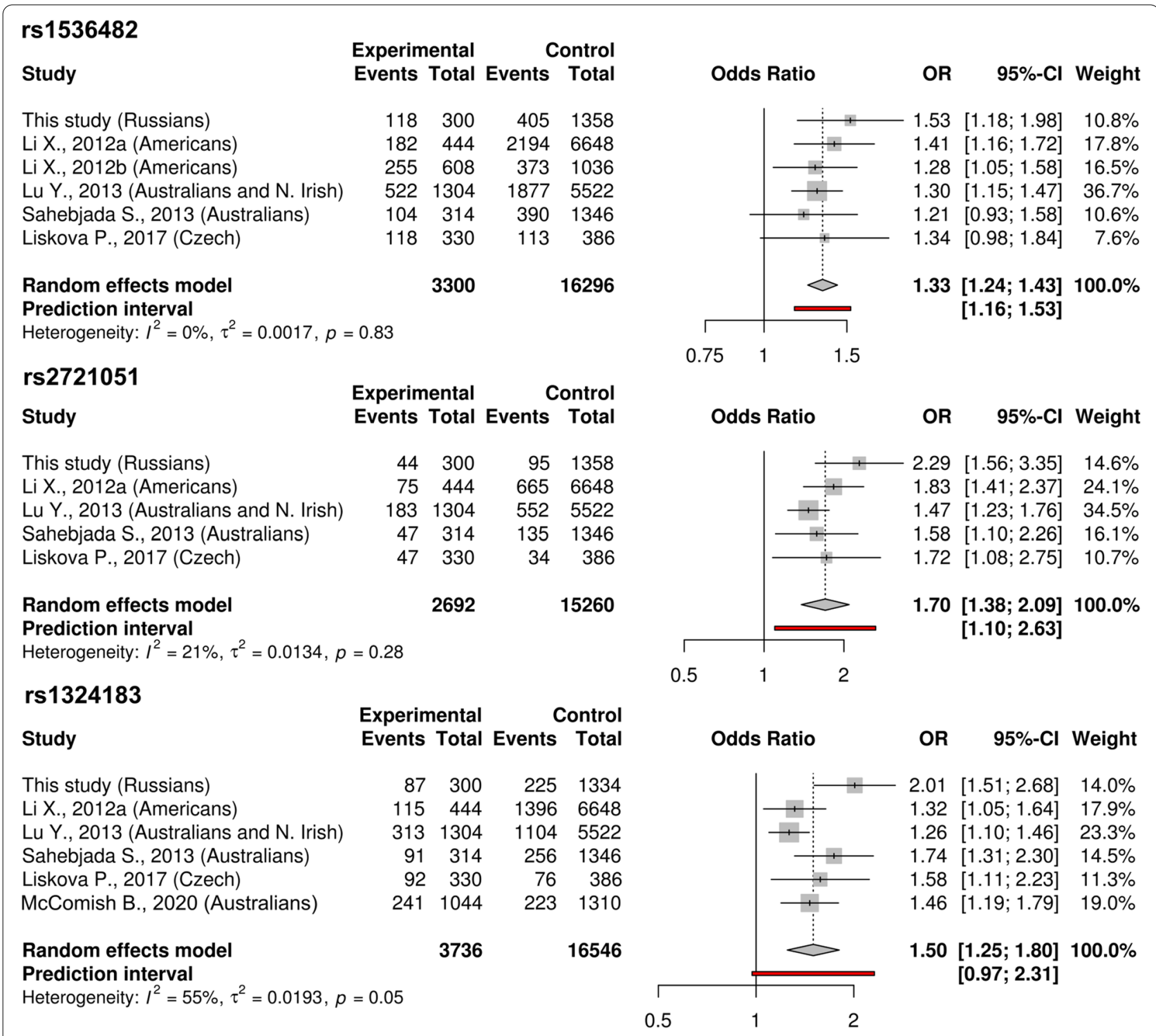

Fig. 1 Meta-analyses of the rs1536482, rs2721051, and rs1324183 variants from keratoconus studies. $\mathbf{a}$ - discovery cohort; $\mathbf{b}$ - replication cohort

Table 6 Rare variants in the COL5A1 promoter in keratoconus patients with the rs 1536482 minor allele/es

\begin{tabular}{|c|c|c|c|c|c|c|c|}
\hline $\begin{array}{l}\text { dbSNP } \\
\text { identification } \\
\text { number }\end{array}$ & $\begin{array}{l}\text { Number of } \\
\text { probands with } \\
\text { variant }\end{array}$ & $\begin{array}{l}\text { Sequence } \\
\text { annotation }\end{array}$ & $\begin{array}{l}\text { MAF ALFA } \\
\text { European }\end{array}$ & Genotypes & $\begin{array}{l}\text { Cosegregation } \\
\text { analysis } \\
\text { available }\end{array}$ & $\begin{array}{l}\text { Number of } \\
\text { cosegregation } \\
\text { analyses }\end{array}$ & Segregation \\
\hline rs1043208782 & 1 & intron & $T=0.00132$ & hetero-zygote & no & N/A & N/A \\
\hline rs569248712 & 1 & 5-UTR & $A=0.00399$ & hetero-zygote & yes & 1 & yes \\
\hline rs548525119 & 3 & exon p.Pro21Ser & $T=0.00021$ & $\begin{array}{l}2 \text { homo- } \\
\text { zygotes/1 } \\
\text { hetero-zygote }\end{array}$ & yes & 2 & 2 no \\
\hline
\end{tabular}


harboring the rs548525119 minor allele, we did not observe segregation in either family. rs569248712 cosegregated with the phenotype.

\section{Discussion}

Here, we present the results of the genotyping of keratoconus-associated SNPs in a Russian cohort of 829 subjects. We found that three selected variants, rs1536482, rs2721051, and rs1324183, had a significant difference in MAFs between the keratoconus and control groups. Additionally, we compared the pooled effect sizes of rs1536482, rs2721051, and rs1324183 from reported keratoconus association studies of European ancestry cohorts to characterize the placement of the Russian keratoconus cohort. We found that rs1536482 and rs2721051 had homogeneous effect sizes in Europeanancestry keratoconus cohorts, including the Russian cohort. This may indicate that these populations exhibit a consistent fraction of patients harboring causal variants in linkage disequilibrium blocks containing minor alleles of these variants. rs1324183 showed a higher OR in the Russian keratoconus cohort than in other European ancestry cohorts. This result reflected the low MHFs (5.4 and $3.4 \%$ ) in the control groups, which may be a specific feature of the Russian population. This finding needs further investigation in larger samples.

SNPs rs1536482, rs2721051, and rs1324183 are located in the intergenic space, so their direct association with nearby genes is uncertain. Nevertheless, we present some data on the possible role of COL5A1 in the pathogenesis of keratoconus. The nearest gene to rs1536482 with a known function is COL5A1, which encodes the collagen type $\mathrm{V}$ alpha 1 chain. Collagen $\mathrm{V}$ type is a regulatory and structural component of collagen fibrils. In the cornea, it assembles with collagen type I into heterotypic collagen fibrils. Mutations in the COL5A1 gene are the most common cause of Ehlers-Danlos syndrome [37]. In patients with Ehlers-Danlos syndrome, mutations in the COL5A1 gene lead to a decrease in corneal thickness and the density of collagen fibrils, similar to the changes observed in keratoconus [38, 39]. The keratoconus patients in our sample did not have Ehlers-Danlos syndrome, so we did not expect them to harbor pathogenic variants in the protein-coding sequence of COL5A1. Additionally, it was previously found that patients with keratoconus do not show enrichment in rare potentially pathogenic variants in protein-coding sequences, and only intron variants of unknown significance were found [40, 41]. Therefore, we considered the possibility that potentially pathogenic variants may be located in the COLSA1 promoter. We sequenced the COL5A1 promoter in a subgroup of keratoconus patients who had at least one rs1536482 minor allele. We identified three rare SNVs. Among these
SNVs, rs548525119 did not cosegregate in relatives. The involvement of rs1043208782 and rs569248712 in keratoconus pathogenesis needs further investigation. These SNVs were present in a small proportion of keratoconus patients (two out of 94). Therefore, we conclude that rare SNVs in the COL5A1 promoter do not play a major role in keratoconus susceptibility associated with rs 1536482. This is consistent with our results showing that the presence of the rs 1536482 minor allele is not associated with the COL5A1 gene expression level [20].

The study is limited by its relatively modest sample size. However, the sample size examined in our study was comparable to those in other candidate gene studies of keratoconus $[10,11]$.

\section{Conclusions}

We found that rs1536482 near the COL5A1 gene, rs2721051 near the FOXO1 gene, and rs1324183 near the MPDZ gene were significantly associated with keratoconus in a Russian cohort. We found two rare variants in the COL5A1 promoter, one of which, rs569248712, cosegregated with the phenotype in the analyzed family.

\section{Abbreviations}

ABI: Applied Biosystems Inc. sequencer trace file format; EDTA: Ethylenediaminetetraacetic acid; GWAS: Genome-wide association study; MAF: Major allele frequency; MHF: Minor homozygote frequency; OR: Odds ratio; PCR: Polymerase chain reaction; SD: Standard deviation; SNP: Single nucleotide polymorphism; SNV: Single nucleotide variant.

\section{Acknowledgments}

We thank the Center for Precision Genome Editing and Genetic Technologies for Biomedicine, Federal Research and Clinical Center of Physical-Chemical Medicine of the Federal Medical Biological Agency for performing SNP array genotyping. The recruitment of volunteers for the group of healthy controls (additional control group) was performed within the Tomsk Polytechnic University Competitiveness Enhancement Program.

\section{Authors' contributions}

$\mathrm{LO}, \mathrm{BE}$, and $\mathrm{El}$ designed the study. LO, ES, and OV performed DNA extraction and genotyping and analyzed genotyping data. $L N, A, R R$, and El analyzed SNP array data. $\mathrm{AV}, \mathrm{MM}, \mathrm{EL}, \mathrm{OP}$, and $\mathrm{BE}$ recruited keratoconus and the main control group participants, conducted ophthalmological examinations, collected participant data, and collected genetic material. OYu, SA, and RR recruited additional control group participants, conducted examinations, collected participants' data and genetic material. LO was the main contributor in writing the draft of the manuscript. AV, El, LN, A, BE contributed to the draft of the article. BE was the Russian Foundation for Basic Research grant recipient; LO, $\mathrm{El}, \mathrm{AV}$, OP were grant executors. A was a recipient of the Saint Petersburg State University Program of development and performed SNP array genotyping in the additional control group. All authors read and approved the final manuscript.

\section{Funding}

Recruitment, blood collection, DNA extraction, SNV genotyping of keratoconus patients and main control group participants was supported by the Russian Foundation for Basic Research, grant 17-29-06077. SNP array genotyping in the additional control group was supported by Saint Petersburg State University (Program of development, \#M15-D3-N1). 


\section{Availability of data and materials}

The datasets used during the current study and $A B I$ trace files are available from the corresponding author on reasonable request.

\section{Declarations}

\section{Ethics approval and consent to participate}

The Institutional Review Boards of the S. Fyodorov Eye Microsurgery Complex Federal State Institution, the Federal Research and Clinical Center of PhysicalChemical Medicine, and the Ufa Eye Research Institute approved this study. It was conducted in compliance with the tenets of the Declaration of Helsinki. All subjects signed written informed consent forms.

\section{Consent for publication}

Not applicable.

\section{Competing interests}

The authors declare that they have no competing interests. The authors declare no support from any organization for the submitted work; no financial relationships with any organizations that might have an interest in the submitted work; and no other relationships or activities that could appear to have influenced the submitted work.

\section{Author details}

${ }^{1}$ Laboratory of Human Molecular Genetics, Federal Research and Clinical Center of Physical-Chemical Medicine of Federal Medical Biological Agency, 1a Malaya Pirogovskaya UI, Moscow, Russian Federation 119435. ²Department of Anterior Segment Transplant and Optical Reconstructive Surgery, S. Fyodorov Eye Microsurgery Complex Federal State Institution, 59a Beskudnikovskiy Blv, Moscow, Russian Federation 127486. ${ }^{3}$ Department of Surgery of the Cornea and Lens, Ufa Eye Research Institute, Academy of Sciences of the Republic of Bashkortostan, 90 Pushkina UI, Ufa, Russian Federation 450008. ' Laboratory for Genomic Research and Computational Biology, Federal Research and Clinical Center of Physical-Chemical Medicine of Federal Medical Biological Agency, 1a Malaya Pirogovskaya UI, Moscow, Russian Federation 119435. ${ }^{5}$ Theodosius Dobzhansky Center for Genome Bioinformatics, Saint Petersburg State University, 7/9 Universitetskaya Nab, Saint Petersburg 199034, Russia. ${ }^{6}$ Laboratory of Molecular Genetics and Biochemistry, Mental Health Research Institute, Tomsk National Research Medical Center, Russian Academy of Sciences, 4 Aleutskaya UI, Tomsk 634014, Russia. ${ }^{7}$ Division for Testing and Diagnostics, National Research Tomsk Polytechnic University, 30 Lenina Prosp, Tomsk 634050, Russia. ${ }^{8}$ Addiction Psychiatry and Psychotherapy Department, Siberian State Medical University, 2 Moskovsky Trakt, Tomsk 634055, Russia. ${ }^{9}$ Laboratory of Neuroscience and Molecular Pharmacology, Institute of Translational Biomedicine and Saint Petersburg State University Hospital, Saint Petersburg State University, 7/9 Universitetskaya Nab, Saint Petersburg 199034, Russia.

Received: 11 July 2021 Accepted: 24 September 2021 Published online: 08 October 2021

\section{References}

1. Mas Tur V, MacGregor C, Jayaswal R, O'Brart D, Maycock N. A review of keratoconus: diagnosis, pathophysiology, and genetics. Surv Ophthalmol. 2017:62(6):770-83.

2. Fernández Pérez J, Valero Marcos A, Martínez Peña FJ. Early diagnosis of keratoconus: what difference is it making? $\mathrm{Br} J$ Ophthalmol. 2014;98(11):1465-6.

3. Giri P, Azar DT. Risk profiles of ectasia after keratorefractive surgery. Curr Opin Ophthalmol. 2017;28(4):337-42.

4. Bohac M, Koncarevic M, Pasalic A, Biscevic A, Merlak M, Gabric N, et al. Incidence and clinical characteristics of post LASIK ectasia: a review of over 30,000 LASIK cases. Semin Ophthalmol. 2018;33(7-8):869-77.

5. Bykhovskaya Y, Rabinowitz YS. Update on the genetics of keratoconus. Exp Eye Res. 2021;202:108398.

6. Li X, Bykhovskaya Y, Haritunians T, Siscovick D, Aldave A, SzczotkaFlynn L, et al. A genome-wide association study identifies a potential novel gene locus for keratoconus, one of the commonest causes for corneal transplantation in developed countries. Hum Mol Genet. 2012;21(2):421-9.

7. Li X, Bykhovskaya Y, Canedo AL, Haritunians T, Siscovick D, Aldave AJ, et al. Genetic association of COL5A1 variants in keratoconus patients suggests a complex connection between corneal thinning and keratoconus. Invest Ophthalmol Vis Sci. 2013;54(4):2696-704.

8. Lu Y, Vitart V, Burdon KP, Khor CC, Bykhovskaya Y, Mirshahi A, et al. Genome-wide association analyses identify multiple loci associated with central corneal thickness and keratoconus. Nat Genet. 2013;45(2):155-63.

9. Bae HA, Mills RA, Lindsay RG, Phillips T, Coster DJ, Mitchell P, et al. Replication and meta-analysis of candidate loci identified variation at RAB3GAP1 associated with keratoconus. Invest Ophthalmol Vis Sci. 2013:54(7):5132-5.

10. Sahebjada S, Schache M, Richardson AJ, Snibson G, MacGregor S, Daniell $M$, et al. Evaluating the association between keratoconus and the corneal thickness genes in an independent Australian population. Invest Ophthalmol Vis Sci. 2013;54(13):8224-828.

11. Liskova P, Dudakova L, Krepelova A, Klema J, Hysi PG. Replication of SNP associations with keratoconus in a Czech cohort. PLoS One. 2017;12(2):e0172365

12. Rong SS, Ma ST, Yu XT, Ma L, Chu WK, Chan TC, et al. Genetic associations for keratoconus: a systematic review and meta-analysis. Sci Rep. 2017;7(1):4620.

13. Iglesias Al, Mishra A, Vitart V, Bykhovskaya Y, Höhn R, Springelkamp H, et al. Cross-ancestry genome-wide association analysis of corneal thickness strengthens link between complex and Mendelian eye diseases. Nat Commun. 2018;9(1):1-11.

14. McComish BJ, Sahebjada S, Bykhovskaya Y, Willoughby CE, Richardson AJ, Tenen A, et al. Association of genetic variation with keratoconus. JAMA Ophthalmol. 2020;138(2):174-81.

15. Lu Y, Dimasi DP, Hysi PG, Hewitt AW, Burdon KP, Toh TY, et al. Common genetic variants near the brittle cornea syndrome locus ZNF469 influence the blinding disease risk factor central corneal thickness. PLoS Genet. 2010;6(5):e1000947.

16. Vitart V, Benčić G, Hayward C, Škunca Herman J, Huffman J, Campbell S, et al. New loci associated with central cornea thickness include COL5A1, AKAP13 and AVGR8. Hum Mol Genet. 2010;19(21):4304-11.

17. Cornes BK, Khor CC, Nongpiur ME, Xu L, Tay WT, Zheng Y, et al. Identification of four novel variants that influence central corneal thickness in multi-ethnic Asian populations. Hum Mol Genet. 2012;21(2):437-45

18. Khawaja AP, Lopez KE, Hardcastle AJ, Hammond CJ, Liskova P, Davidson $A E$, et al. Genetic variants associated with corneal biomechanical properties and potentially conferring susceptibility to keratoconus in a genomewide association study. JAMA Ophthalmol. 2019;137(9):1005-12.

19. Simcoe MJ, Khawaja AP, Hysi PG, Hammond CJ. UK biobank eye and vision consortium. Genome-wide association study of corneal biomechanical properties identifies over 200 loci providing insight into the genetic etiology of ocular diseases. Hum Mol Genet. 2020;29(18):3154-64

20. Skorodumova LO, Belodedova AV, Zakharova ES, Sharova El, Bikbov MM Usubov EL, et al. Association of single nucleotide variants in the COL5A1 gene and adjacent intergenic space with keratoconus in a cohort of patients from Russia. Fyodorov J Ophthalmic Surg. 2020;1:6-13 Russian.

21. Krumeich JH, Daniel J, Knülle A. Live-epikeratophakia for keratoconus. J Cataract Refract Surg. 1998;24(4):456-63.

22. Hughes AE, Bradley DT, Campbell M, Lechner J, Dash DP, Simpson DA, et al. Mutation altering the miR-184 seed region causes familial keratoconus with cataract. Am J Hum Genet. 2011;89(5):628-33.

23. Levchenko A, Kanapin A, Samsonova A, Fedorenko OY, Kornetova EG, Nurgaliev T, et al. A genome-wide association study identifies a gene network associated with paranoid schizophrenia and antipsychoticsinduced tardive dyskinesia. Prog Neuro-Psychopharmacol Biol Psychiatry. 2021:105:110134

24. Okonechnikov K, Golosova O, Fursov M. UGENE team. Unipro UGENE: a unified bioinformatics toolkit. Bioinformatics. 2012;28(8):1166-7.

25. Haeussler M, Zweig AS, Tyner C, Speir ML, Rosenbloom KR, Raney BJ, et al. The UCSC genome browser database: 2019 update. Nucleic Acids Res. 2019;47(D1):D853-8.

26. ENCODE Project Consortium. An integrated encyclopedia of DNA elements in the human genome. Nature. 2012;489(7414):57. 
27. Purcell S, Neale B, Todd-Brown K, Thomas L, Ferreira MA, Bender D, et al. PLINK: a tool set for whole-genome association and population-based linkage analyses. Am J Hum Genet. 2007;81(3):559-75.

28. Delaneau O, Zagury JF, Marchini J. Improved whole-chromosome phasing for disease and population genetic studies. Nat Methods. 2013;10(1):5-6.

29. Howie BN, Donnelly P, Marchini J. A flexible and accurate genotype imputation method for the next generation of genome-wide association studies. PLoS Genet. 2009;5(6):e1000529.

30. 1000 Genomes Project Consortium. A global reference for human genetic variation. Nature. 2015;526(7571):68

31. Faul F, Erdfelder E, Buchner A, Lan A-G. Statistical power analyses using $G^{*}$ power 3.1: tests for correlation and regression analyses. Behav Res Methods. 2009;41:1149-60.

32. R Core Team. R: A language and environment for statistical computing. $R$ Foundation for Statistical Computing, Vienna, Austria. http://www.R-proje ct.org/.

33. Schwarzer G. meta: an R package for meta-analysis. R News. 2007;7(3):40-5.

34. IntHout J, loannidis JP, Borm GF. The Hartung-Knapp-Sidik-Jonkman method for random effects meta-analysis is straightforward and considerably outperforms the standard DerSimonian-Laird method. BMC Med Res Methodol. 2014;14(1):25.

35. Higgins JPT, Thompson SG, Deeks JJ, Altman DG. Measuring inconsistency in meta-analyses. BMJ Br Med J. 2003;327(7414):557-60.
36. Phan $L$, Jin $Y$, Zhang $H$, et al. ALFA: Allele Frequency Aggregator. National Center for Biotechnology Information, U.S. National Library of Medicine, 10 Mar. 2020, www.ncbi.nlm.nih.gov/snp/docs/gsr/alfa/.

37. Symoens S, Syx D, Malfait F, Callewaert B, De Backer J, Vanakker O, et al. Comprehensive molecular analysis demonstrates type $\mathrm{V}$ collagen mutations in over $90 \%$ of patients with classic EDS and allows to refine diagnostic criteria. Hum Mutat. 2012;33(10):1485-93.

38. Segev F, Héon E, Cole WG, Wenstrup RJ, Young F, Slomovic AR, et al. Structural abnormalities of the cornea and lid resulting from collagen $V$ mutations. Invest Ophthalmol Vis Sci. 2006;47(2):565-73.

39. Mathew JH, Goosey JD, Bergmanson JPG. Quantified histopathology of the keratoconic cornea. Optom Vis Sci. 2011;88(8):988-97.

40. Lucas SE, Zhou T, Blackburn NB, Mills RA, Ellis J, Leo P, et al. Rare, potentially pathogenic variants in 21 keratoconus candidate genes are not enriched in cases in a large Australian cohort of European descent. PLoS One. 2018;13(6):e0199178.

41. Fransen $E$, Valgaeren $H$, Janssens $K$, Sommen M, De Ridder R, Vandeweyer G, Bisceglia L, Soler V, Hoischen A, Mortier G, Malecaze F. Resequencing of candidate genes for Keratoconus reveals a role for Ehlers-Danlos Syndrome genes. Eur J Hum Genet. 2021:1-11.

\section{Publisher's Note}

Springer Nature remains neutral with regard to jurisdictional claims in published maps and institutional affiliations.
Ready to submit your research? Choose BMC and benefit from:

- fast, convenient online submission

- thorough peer review by experienced researchers in your field

- rapid publication on acceptance

- support for research data, including large and complex data types

- gold Open Access which fosters wider collaboration and increased citations

- maximum visibility for your research: over $100 \mathrm{M}$ website views per year

At BMC, research is always in progress.

Learn more biomedcentral.com/submissions 